\title{
Minimal Intervention in Dental Care
}

\author{
Aubrey Sheiham \\ Department of Epidemiology and Public Health, University College, London, UK
}

\section{Key Words}

Dental care · Evidence-based dentistry $\cdot$ Effectiveness

\begin{abstract}
High-quality appropriate dental care should encompass the concepts of effectiveness and efficiency. Many dental procedures are ineffective, and some preventive measures are inefficient. Examples of criteria that are ethically essential to use before carrying out any clinical procedure are outlined based on the concepts included in 'informed consent'. Applying the criteria rigorously will lead to minimal intervention and a more equitable distribution of appropriate dental care. Unnecessary dental care will be reduced.
\end{abstract}

Copyright @2002 S. Karger AG, Basel

\section{Minimal Intervention in Dental Care}

Dentistry is based on the implicit assumption that treatment of disease by dentists would achieve improved health and that resources are available to fund their efforts. In an era of evidence-based medicine and dentistry, such an attitude is no longer acceptable. The best dentistry is no dentistry. Faced with unequivocal evidence that most dental caries and periodontal diseases can be prevented at low cost with available public health preventive measures, the ethical imperative to prevent what is preventable and reduce clinical intervention to a minimum is very strong. And when dental care is needed, it should be of high quality and based upon evidence of efficacy, effectiveness and efficiency. Efficacy asks the question: 'Can it work?' It is the extent to which an intervention does more good than harm under ideal conditions. Effectiveness is: 'Does it work in practice?' Here we assess whether an intervention does more good than harm when provided under usual general practice circumstances. Efficiency measures the effect of the intervention in relation to the resources it consumes and asks the question: 'Is it worth it?' [1].

High-quality appropriate dental health care should encompass effectiveness and efficiency. Furthermore, quality includes the consistent and reliable delivery of costeffective dental care which is faithful to the values of the society where the care takes place, is feasible, considers the available resources and is responsive to individual needs and values of care recipients. The concepts of effectiveness and efficiency are central to evidence-based medicine, first introduced by Cochrane [1]. To practice quality dentistry, evidence-based dentists should base their interventions on 'conscientious, explicit and judicious use

\begin{tabular}{ll}
\hline KARGER & ( ) 2002 S. Karger AG, Basel \\
Fax +4161306 1234 $341571 / 02 / 0115-0002 \$ 18.50 / 0$ \\
$\begin{array}{l}\text { E-Mail karger@karger.ch } \\
\text { www.karger.com }\end{array}$ & $\begin{array}{l}\text { Accessible online at: } \\
\text { www.karger.com/journals/mpp }\end{array}$
\end{tabular}

\footnotetext{
Prof. Aubrey Sheiham

Department of Epidemiology and Public Health

University College London, 1-19 Torrington Place

London WC1E 6BT (UK)
}

Fax+44 1718130280 , E-Mail a.sheiham@ucl.ac.uk 
of current best evidence in making decisions about care of individual patients. The practice of evidence-based medicine means integrating individual clinical expertise with the best available external clinical evidence from systematic research. By individual clinical expertise, we mean the proficiency and judgment that individual clinicians acquire through clinical experience and clinical practice.

'... By best available external clinical evidence we mean clinically relevant research ...' [2].

Clinical expertise is one part of quality. If dental health professionals are seriously committed to quality, there is no other way to achieve this than by listening to their patients and by adopting an ethical approach which includes the frank and honest answering of the questions required for obtaining informed consent before intervening. Indeed, the concept of informed consent, if practiced fully, ensures that most aspects of evidence-based dental care are fulfilled. Therefore, it is worthwhile outlining the requirements for informed consent stipulated by the General Medical Council of Great Britain [3], i.e. patients must be given sufficient information, in a way that they can understand, in order to enable them to exercise their right to make informed decisions about their care. The information which patients want or ought to know, before deciding whether to consent to treatment or an investigation, may include:

The diagnosis and prognosis, namely uncertainties about the diagnosis, options for further investigation prior to treatment, the likely prognosis if the condition is left untreated and options for treatment and management, both standard and experimental;

the proposed investigation or treatment, namely its purpose, the procedure(s) or therapies involved, including subsidiary methods such as pain relief, preparatory information as to what the patient will/might experience during the procedure, common and serious side-effects and a plan for monitoring.

It is incumbent upon the dentist to provide this information in a way patients can understand, reflecting respect for the right of patients to be fully involved in decisions concerning their care. It is also the responsibility of the dentist to remain up-to-date in his professional knowledge and to recognize the limits of his professional competence. Finally, his dealings with patients must be entirely honest so as to inspire their trust.

Dentists therefore need to know the likely benefits of their treatment and side-effects and alternative options. What is the evidence for the effectiveness and efficiency of dental procedures?

Minimal Intervention in Dental Care

\section{Evidence-Based Dentistry}

Until recently, the most common dental procedures have not been critically evaluated to assess their effectiveness. The failure rate for posterior dental restorations is high. Between 50 and $75 \%$ of all amalgam restorations were replaced within 10 years and the median longevity was $7-8$ years $[4,5]$. The figures for posterior restorations in deciduous teeth are much poorer. Posterior composites have half the longevity of amalgams [4].

The variable life expectancy of various types of dental restorations has been reviewed [6]. Senior members of the dental profession acknowledge that 'there was little health gain from some of the dental services provided and lack of evidence-based treatment decisions' [7]. Most orthodontic treatments have not been subjected to random controlled trials; however, procedures which have not been shown to be effective or give significant health gain include:

- extractions of asymptomatic third molars [8];

- replacing missing molars [9];

- prophylaxis, including scale and polish [10];

- chairside dental health education [11];

- unsupervised brushing and flossing to improve gingival health [11];

- 6-monthly recall intervals $[12,13]$

- combinations of topical fluoride therapies [14].

Some of the time-consuming activities that dentists do are ineffective, and in the present climate of evidencebased dentistry, clinical governance and consumer sovereignty, such activities should be curtailed. In spite of evidence showing that the current methods and systems of dental care are ineffective, costly and not very well accepted by the public, decision makers and an influential part of the dental profession remain preoccupied with availability of care and finance.

The selective elimination of inappropriate care would free resources to provide effective care to those who need it. One way of doing this is by developing high-quality, flexible appropriateness criteria, which can be used both to measure past performance and to guide clinical decision making.

\section{Review of Two Ineffective Concepts in Dentistry}

Two commonly performed ineffective dental procedures will be used to illustrate how unquestioning dental educators and planners have been in accepting convention. These two procedures are recall intervals, and scale and polish.

Med Principles Pract 2002;11(suppl 1):2-6 


\section{Recall Examinations}

The 6-monthly recall interval has been recommended for over 140 years. One of the first references to the 6monthly visit was by George Quickshank in 1849. Although this dogma existed for over 150 years, it has never been scientifically tested [12]. The maintenance of a 6monthly visit shows a lack of knowledge about the life history of dental diseases. Dentists consider that all teeth are little time bombs. The question is not will they go bad, it is when. As a result they monitor constantly. As dental diseases develop slowly, the hallowed 6-monthly recall interval should be extended. Sheiham [12] carried out a review of the evidence for routine 6-monthly recalls. Surprisingly, no scientific evidence for the 6-monthly recall was found. Trends in dental disease since 1977 strengthen the evidence against frequent recalls at intervals of less than 2 years. Indeed, studies in Norway showed that there was no health gain for over $90 \%$ of children in having dental checks at intervals from 18 months to 2 years [13]. For those over 20 years, longer intervals of up to $3-5$ years are recommended [12]. In addition, an expert group has reviewed the basis for routine dental radiographs. They recommend that, except for high-risk children, radiographs at intervals of 2 years or longer are recommended [15].

\section{Scaling and Polishing Teeth}

Most studies show that the need for periodontal treatment is relatively low. Since most gingival inflammation does not progress to periodontitis, it is not clear whether prevention or treatment of all gingivitis is necessary for preventing destructive periodontal diseases. Severe periodontal diseases occur in a few teeth in a relatively small proportion of people in any given age cohort. The low prevalence of severe symptoms of periodontal disease is a reason to rethink the nature and extent of periodontal disease as a dental health problem [16]. Earlier concepts of periodontal disease suggested that gingival inflammation invariably progressed to periodontitis and that untreated periodontitis progressively destroys the periodontium, ultimately leading to severe periodontal disease and tooth loss. The answer to the question 'Does gingivitis always progress to periodontitis?' is 'Clearly, not all gingivitis progresses to periodontitis ...' [17]. The concept of invariable progression from gingivitis to periodontitis was first challenged by Page and Schroeder [18] and later by Goodson et al. [19]. The 'burst' theory [19] incorporates the concept of 'contained gingivitis' and 'stable gingivitis' [20] to classify gingival inflammation as that which is limited to the gingivae. Goodson et al. [19] suggested that gingival inflammation frequently remains contained and, for reasons yet to be elucidated, progresses to periodontal breakdown at some sites around some teeth. Many inflamed gingival sites remain free of destructive periodontal disease for a lifetime. They concluded that 'a dynamic condition of disease exacerbation and remission as well as periods of inactivity may be characteristic of periodontal disease'. Periodontitis is always preceded by gingivitis, but most gingivitis remains stable for years without progressing to periodontitis [21-23].

Calculus does not have a major role in the pathogenesis of periodontal diseases. Apart from social reasons, the clinical basis for calculus removal is unjustified. Supragingival calculus is not a direct cause of periodontal disease, and levels of calculus have decreased due to the decrease in smoking, improved oral cleanliness and the wider use of antitartar and therapeutic toothpastes.

Professional oral hygiene procedures such as scale and polish and oral hygiene instruction are largely ineffective. There is no evidence that there is any health gain from scaling and polishing teeth [24, 25].

What are the benefits and side-effects of routine scaling of teeth? In a state-of-the-science review of mechanical oral hygiene practices, Frandsen [10] came to some important conclusions about very common procedures. His conclusions are still relevant as no counter-evidence has been produced. Frandsen's conclusions were:

- scaling and oral hygiene instruction did not markedly affect the gain or loss of attachment;

- there was some doubt about the usefulness of removing calculus and no evidence that removal of plaque at intervals longer than 4 weeks was of significant therapeutic benefit;

- no studies have been found to demonstrate the additional benefits of root planing as compared to removal of calculus and overhangs;

- the role of root planing in preventing reinfection of the subgingival area is questionable;

- scaling, polishing, root planing and surgical treatment of shallow periodontal pockets results in permanent loss of attachment;

- the optimal frequency and starting age for scaling and polishing has not been determined.

A recent systematic review of 144 studies on the effectiveness of scale and polish performed more frequently than once a year compared to once a year concluded that there was very little gain in periodontal health from more frequent scalings [26]. We do not pay doctors to clean their patients' toenails. Why do we pay dental workers to clean people's teeth, a procedure which has questionable 
health benefit and may lead to loss of periodontal attachment?

In addition to these conclusions, the findings in the systematic review by Kay and Locker [11] that chairside dental health education was ineffective in reducing periodontal disease or caries demonstrated that there is little scientific justification for prophylaxis and chairside dental health education. Should we therefore speculate that the economic rationale for preventive measures is doubtful? At low levels of disease, the returns from chairside prevention are too small to justify the intervention. In the case of caries, the cost per lesion saved increases as the level of decay decreases. At the lower levels of dental caries now prevailing, the traditional preventive methods such as fluoride rinsing, professionally applied fluorides and intensive chairside dental health education cannot be justified because they are no longer cost effective.

This review has shown that some very common procedures are of questionable efficacy and efficiency. The ethics of performing them should be assessed. Can a dentist in all honesty continue to carry out such procedures without informing decision makers and the public that there is no evidence for doing them? Such an unethical interventionist approach is unjustified. 'Less is beautiful' should be the criterion for clinical intervention. The alternative 'tooth death spiral' approach is ineffective, painful and expensive.

\section{The Tooth Death Spiral}

An interventionist orientation to dental diseases leads to a spiral of damage. As dentists think they are looking after a machine which is constantly breaking down, they do not allow it to repair or heal because they do not consider the natural history of disease. More seriously, the present systems of dental care - treating disease after it has occurred - are ineffective and iatrogenic and, at best, palliative. Decisions made by dentists for replacing a filling are idiosyncratic [27]. The decisions bear very little relationship to rational decision making. The restorations get larger each time they are replaced and frequently fail because of the failure to assess the reason for the causes of the failure [28]. This leads to a perpetuation of the errors and increasing complexity of the restoration. The more fillings that are replaced, the greater the probability of overhangs and other forms of iatrogenic damage. The dental bur causes notches in the teeth adjacent to where cavities were prepared in $95 \%$ of cases. Larger fillings cost more with consequences for the availability of 'complex care'. The more complex the restorations, the more problems resulting in toothache and discomfort. The more toothache, the more teeth require root fillings and extractions. This cycle of repair of repair is recognized as the 'tooth death spiral'. In essence, the current system of dental care, called the engineering approach, leads to a tooth death spiral and spiraling costs [29].

More fillings at the onset result in more new and replacement fillings. Very few of the fillings that are placed are new fillings. For every replacement there is a decrease in the life expectancy of the subsequent filling. By the time the fifth filling is done in a tooth, the life expectancy compared to the first filling has been reduced to one third, and the fillings become much more complex [30]. The costs spiral, and the fillings require more and more servicing. Tooth loss is followed by replacements by either dentures, bridges or implants. In Sweden and Germany, two countries where the restorative approach has been carried to an extreme, they now talk of a third dentition, the implanted dentition.

Intervention leads to a spiral of damage and a failure to cope with dental disease. That is not to say that routine dental treatments are always ineffective. They can be of help, but all too often they are insignificant compared to the overall failure of dentistry to actually do what is really needed. Severe criticism of the restorative approach was made by the Committee of Enquiry into Unnecessary Dental Treatment (the Schanschieff Report), which was set up by the Minister of Health of the UK following public concern about dental treatment [31]. They found that '... the restorative approach was at the heart of unnecessary treatment' and concluded that '... we have gone beyond the stage where there are in the profession two respectable alternative approaches, the restorative and the preventive. It is now clear that those who follow the restorative approach and carry out more than the minimum number of restorations necessary are undertaking unnecessary treatment.' There is a need to change the emphasis of dentistry from technological repair by encouraging practitioners '... to limit intervention to the absolute minimum and to give prevention the prevention the opportunity to work' [32].

\section{Conclusions}

Limiting intervention to the absolute minimum and giving prevention the opportunity to work should be the basis for quality dental care. By preventing what is preventable, and only treating when absolutely necessary 
using evidence-based procedures and materials, dentists can provide dental care to large numbers of people at low cost. The prime responsibility of planners of dental care is to ensure that dental care services are based on sound evidence and that the rewards and incentives for dental health workers make quality decisions about treatment and prevention easy decisions. The latter can be achieved by setting goals related to health and not items of treat- ment and rewarding minimal intervention. The payment system should be based upon capitation and not fee-foritem, because the latter system encourages intervention. Dental educators should ensure that evidence-based dentistry is the core concept in their teaching and that students are encouraged to comply with the concepts of informed consent.

\section{References}

1 Cochrane AL: Effectiveness and Efficiency: Random Reflections on Health Services. London, Nuffield PH Trust, 1972.

2 Sackett DL, Rosenberg WMC, Muir Gray JA, Haynes RB, Scott Richardson W: Evidencebased medicine: What it is and what it isn't. BMJ 1996;312:71-72.

3 GMC: Seeking Patients' Consent: The Ethical Considerations. London, General Medical Council, 2000.

4 Mjor IA: Problems and benefits associated with restorative materials: Side-effects and long term cost. Adv Dent Res 1992;6:7-16.

5 Mjor IA, Jokstad A, Qvist V: Longevity of posterior restorations. Int Dent J 1990;40:11-17.

6 Effective Health Care: Dental restoration: What type of filling? York, NHS Centre for Reviews and Dissemination, 1999, vol 5, No 2, www.york.ac.uk/inst/crd.

7 British Dental Association: Thinking the unthinkable. Symposium at BDA, Dec 1996. BDA News Suppl 1996, pp 1-4.

8 National Institute for Clinical Excellence: Technology Appraisal No 1: Guidance on removal of wisdom teeth. NICE, March 2000, www.nice.org.uk.

9 Elias AC, Sheiham A: The relationship between satisfaction with mouth and number and position of teeth. J Oral Rehab 1998;25:649_ 661.

10 Frandsen A: Mechanical oral hygiene practises; in Loe H, Kleinman DV (ed): Dental Plaque Control Measures and Oral Hygiene Practices. Oxford, IRL Press, 1986, pp 93-116.

11 Kay EJ, Locker D: Is dental health education effective? A systematic review of current evidence. Community Dent Oral Epidemiol 1996; 24:231-235.
12 Sheiham A: Is there a scientific basis for sixmonthly dental examinations? Lancet 1977; ii:442-444.

13 Wang N, Marstrander P, Holst D, Ovrum L, Dahle T: Extending recall intervals - Effect on resource consumption and dental health. Community Dent Oral Epidemiol 1992;20:122124.

14 Marinho V: Fluoride Rinses for Preventing Dental Caries in Children and Adolescents. Manchester, Cochrane Reviews, 2000.

15 Royal College of Surgeons: Selection Criteria for Dental Radiography Faculty of General Dental Surgery (UK). London, Royal College of Surgeons, 1998.

16 Sheiham A: Is the chemical prevention of gingivitis necessary to prevent severe periodontitis? Periodontol 2000 1997;15:15-24.

17 Brown JL, Loë H: Prevalence, extent, severity and progression of periodontal disease. Periodontol 2000 1993;2:57-71.

18 Page RC, Schroeder HE: Periodontitis in Man and Other Animals: A Comparative Review. Basel, Karger, 1982.

19 Goodson JM, Tanner ACR, Haffajee AD, Sornberger GC, Socransky SS: Patterns of progression and regression of advanced destructive periodontal disease. J Clin Periodontol 1982;10:298-310.

20 Ranney RR: Classification of periodontal diseases. Periodontol 2000 1993;2:13-25.

21 Socransky SS, Haffajee AD, Goodson JM, Lindhe J: New concepts of destructive periodontal disease. J Clin Periodontol 1984;11: 21-32.

22 Lindhe J, Haffajee AD, Socranksy SS: Progression of periodontal disease in the absence of periodontal therapy. J Clin Periodontol 1983; 10:433-442.
23 Listgarten MA, Schifter CC, Laster L: 3-year longitudinal study of the periodontal status of an adult population with gingivitis. J Clin Periodontol 1985;12:225-238.

24 Pilot T: Analysis of the overall effectiveness of treatment of periodontal disease; in Shanley D (ed): Efficacy of Treatment Procedures in Periodontics. Chicago, Quintessence, 1981, pp 213-220.

25 Antczak-Boukoms A: Natural history of periodontitis and a review of technologies to prevent and treat it. J Dent Educ 1994;58:625640.

26 Elley K, Burls A, Gold L, Gray M: Scale and Polish for Chronic Periodontal Disease. Birmingham, Department of Health and Epidemiology, West Midlands Development and Evaluation Service, 2000.

27 Elderton RI, Nuttall NM: Variation among dentists in planning treatment. Br Dent J 1983; 154:201-206.

28 Elderton RJ: The quality of amalgam restorations; in Allied HA (ed): Series of Monographs in the Assessment of the Quality of Dental Care. London, London Hospital Medical College, 1977, pp 45-79.

29 McKeown T: The Role of Medicine. Oxford, Blackwell, 1979.

30 Gray JC: An evaluation of the average lifespan of amalgam restorations; MSc dissertation, Department of Community Dental Health, London Hospital Medical College, 1976.

31 DHSS: Committee of Enquiry into Unnecessary Dental Treatment: The Schanschieff Report. London, HMSO, 1986.

32 DHSS: Towards Better Dental Health - Guidelines for the Future: Report of the Dental Strategy Review Group. London, DHSS, 1981. 